\title{
Heavy metals contamination, inauspicious wallop on microbial diversity and their possible remediation for environmental restoration
}

\begin{abstract}
Increasing the large scale use of heavy metals in industries is creating a toxic environment for all living organisms. These metals react at even low concentrations and have received increasing attention worldwide. The refractory and insistent nature of heavy metals leads to severe threat to environment supremacy and life. The native microbial populations in natural sink especially agricultural soils in most parts of the world are being adversely affected by the increasing concentration of metals. The microbial consortiums maintain the soil health with better crop productivity and increase the sustainability of the environment with vital benefits to all living entities. Generally the toxic metals reduce soil fertility with gradual increase input to the food web causing severe public health concerns. This is urgent need of time to mitigate the metal toxicity enigma by cutting edge research with minimizing anthropogenic activities which finally lead to generous release of toxic metals into the environment deliberately with exploitation of the environment and natural resources. Several promising technologies including bioremediation have made understanding of metalmicrobe interactions and their application for mitigation of the toxicity problem. This mini review reveals adverse effect of heavy metals on microbial diversity with deterioration of the human life quality through deep allusion to sustainable agriculture and ecofriendly environment.
\end{abstract}

Keywords: heavy metal, microbial consortium, anthropogenic activities, bioremediation
Volume 5 Issue I - 2017

\author{
Sanjay Kumar,' Priyanka Sangam, ${ }^{2}$ Rajeeva \\ Gaur $^{3}$ \\ 'Department of Microbiology, Bundelkhand University, India \\ ${ }^{2}$ Department of Environmental Science, Shobhit University, India \\ ${ }^{3}$ Department of Microbiology, Dr. Ram Manohar Lohia Avadh \\ University, India
}

\begin{abstract}
Correspondence: Sanjay Kumar, Assistant Professor,
Department of Microbiology, Bundelkhand University, Jhansi, UP, India,Tel +9194535 I5I43,Email sanjay_microbio@yahoo.co.in
\end{abstract}

Received: May 22, 2017 | Published: July 13, 2017

\section{Introduction}

Heavy metal pollution is being considered as a major environmental problem because metal ions persist in the environment due to their non-degradable nature. The goal in bioremediation is to stimulate microorganisms with enriching nutrients that enable them to decontaminate or biotransform the pollutants. Microbial consortiums constitute a massive and mysterious reservoir of resources likely to provide innovative applications useful to human. These entities have ability to regulate heavy metal accumulation by plants and reducing the risks associated with the pollutants. Microbial bioremediation reveals the wise use of microorganisms to clean up hazardous contaminants in soil and wastewater. Generally microbial cells transform them to chemical products no longer hazardous to human health and the environment. Bioremediation involving plants and microbes seems to be a promising tool to reduce pollutant concentrations and clean-up of contaminated environments economically and efficiently. Growing awareness of the harmful effects of environmental pollution has led to a marked increase in research into various strategies that might be used to clean up the contaminated environment. Microbial metabolism is now accepted as a safer and efficient tool for the removal of many such organic pollutants. Microbial population including diversity, activity and genetic structures are affects by the toxicity by altering the nucleic acid, cell membranes disruption, inhibiting enzyme activity. The microbial diversity in true sense can be maintained by wise use of organic inputs in agricultural land following the innovative stateof-the-art for crop productivity which may shape the better health and life with sustainable development.

\section{Discussion}

Heavy metals in soil and water are serious health problems in most of the countries. The most common heavy metals at hazardous waste sites are Cadmium $(\mathrm{Cd})$, Lead $(\mathrm{Pb})$, Chromium $(\mathrm{Cr})$, Copper $(\mathrm{Cu})$, Mercury ( $\mathrm{Hg})$, Nickel (Ni) and Zinc (Zn) which are posing serious health hazards to human and animals (Ulceration, Osteomalacia and Obstructive lung disease etc). Contamination of the environment with heavy metals has increased beyond the recommended limit and is detrimental to all life forms. ${ }^{1}$ Organic matter content has a strong influence on the cation exchange capacity, buffer capacity, as well as on the retention of heavy metals. Thus, metals present in organic soils contaminated with a combination of heavy metals are less mobile and less bioavailable to microorganisms and plants, than metals present in mineral soils. ${ }^{2}$ Some of the heavy metals are essential micronutrients for higher plants. However in toxic concentration these can significantly contribute to soil contamination. Heavy metal contamination is rarely due to a single element mostly several elements are usually simultaneously present in higher concentrations in soil to affect plant and microbial growth. ${ }^{3}$ Soil organic matter tends to have a variety of charged sites on their surfaces, some positive and some negative. The negative charges of these various soil particles tend to attract and bind the metal cations and prevent them from becoming soluble and dissolved in water. The soluble form of metals is thought to be more harmful because it is easily transported and more readily available to plants and animals. Once the metal and metalloid are bound, microbial cells can transform them from one oxidation state to another, thus reducing their toxicity. ${ }^{4}$ By contrast, soil bound 
metals tend to stay in place. In situ bioremediation by indigenous microbial population is an increasing by popular, ecofriendly option for cleanup of contaminated sites and currently considerable effort is being made to design cheap and feasible strategies using this technology, which shows promise as a potential alternative. Besides organic matter persistence organic pollutants are hazardous to mostly all forms of time specially the economic crops. However, an important factor limiting the bioremediation of sites contaminated with the hazardous compounds is the slow rate of degradation. ${ }^{5}$ Bioremediation utilizes the natural role of microorganisms in transformation, mineralization by directing those capabilities toward organic and inorganic environmental pollutants. Microorganisms are ubiquitous, inhabiting even in the most hostile environments. Their ability to transform virtually all forms of organic material makes them attractive agents of bioremediation. Microorganisms interact with metal ions through cell wall associated metals, intracellular accumulation, metalsiderophore, extracellular polymeric reactions with transformation, extracellular mobilization or immobilization of metal ions, and volatilization of metals. ${ }^{6}$ There are many reasons why organic pollutants may not be quickly degraded when dumped into a soil environment having high concentrations of pollutants, limited amounts of electron acceptors, inadequate supply of nutrients, and unfavorable environmental conditions such as moisture, temperature, $\mathrm{pH}$, ionic strength, or redox status. Different organic pollutants that are present in the environment persist for varying periods of time. Depending on their half life, some pollutants either disappear within a short period of time owing to hydrolysis and microbial activities or transformed into non-toxic end products. ${ }^{7}$ Microbes represent by far the richest inventory of molecular and chemical diversity in nature. Microorganisms do not live in isolation but in complex biological communities within which exist complex interactions arising from biotic and abiotic influences. ${ }^{8}$ It is difficult to relate single species behaviors to the overall ecosystem. The understanding of interactions between external stress factors on different biological processes provide a stronger systematic background to offset negative consequences of climatic changes on plants growing in metal polluted soils. Several plant associated microbes are tolerant to various stress conditions with drought, pesticides, heavy metals and temperature. Indeed these microbes might have various plant growth promoting traits necessary to establish the plants under the conditions prevailing in metal polluted soils. ${ }^{9}$ In the expedition to look at other resources, it is important to assess the unexplored unculturable microbial wealth. It has been estimated that $1 \mathrm{~g}$ of soil might contain between 1000 and 10000 species of unknown prokaryotes and likely to be further diversity within each species. ${ }^{10}$ Bioremediation is based on the idea that all organisms remove substances from the environment to carry out growth and metabolism. Bacteria, protista and fungi are found to be very good at degrading complex molecules and incorporating the breakdown products into their metabolism. ${ }^{11}$ Bioaccumulation of metals by various micro- and microorganisms is reported under various conditions. ${ }^{12}$ The resultant metabolic wastes that they produce are generally safe and somehow recycled into other organisms. Bioremediation does not involve only the degradation of pollutants but also, at times it is sufficient to remove the pollutant from the environment without degrading it. ${ }^{13}$ Bacteria in particular take up large amounts of metals and minerals to ensure adequate resources for binary fission. Algae and plants are very good at absorbing nitrogen, phosphorus, sulphur and many minerals and metals from the environment. For example, plants like locoweed remove large amounts of the toxic element selenium. ${ }^{14}$ Microorganisms can be isolated from almost any environmental conditions. Microbes will adapt and grow in excess of oxygen and in anaerobic conditions as well as in presence of hazardous compounds. Further research, both fundamental and applied is necessary. Microbiological and ecological researches are needed to understand more fully the ability of microbes in bioremediation. Soil microbial diversity is an important index of agricultural productivity. ${ }^{15}$ For the evaluation and characterization of microbial diversity, DNA markers including the RAPDs produced by PCR can be used. ${ }^{16}$ As in postulated sequence of possible events progress in bioremediation techniques need more application of basic practices.

\section{Conclusion}

A complete understanding is needed for the biological nature of the approaches which include the interaction among soils, contaminants, microbes and plants. This complex interaction is affected by a variety of factors such as climatic conditions and soil properties, which favor site specific bioremediation practices. The study of microbial diversity is thus important to solve new and emerging disease evils and to move ahead for prosperity and holistic development. Microbial diversity for correct \& accurate characterization of isolates up to species level is not enough, because isolates identified in such a manner may show similarity, but in actual sense, they may belong to different species which are being adversely affected by various ways of toxicity. So for accurate identification of each isolates up to species level need to be the proper implication of cutting edge research techniques. Deep study, assessment and exploitation of microbial diversity are crucial for systematic and industrial development. This time we must not only be more careful of the drastic overuse of heavy metals in our industries, but also more aware of other chemical and pesticides etc, that we put into the environment for avoiding adverse impact on microbial diversity including the safe life for all living entities.

\section{Acknowledgements}

None.

\section{Conflict of interest}

The author declares no conflict of interest.

\section{References}

1. Dixit R, Malaviya D, Pandiyan K, et al. Bioremediation of heavy metals from soil and aquatic environment: An overview of principles and criteria of fundamental processes. Sustainability. 2015;7(2):2189-2212.

2. Olaniran AO, Balgobind A, Pillay B. Bioavailability of heavy metals in soil: Impact on microbial biodegradation of organic compounds and possible improvement strategies. Int J Mol Sci. 2013;14(5):10197-10228.

3. Preeti Pande, Sukhmal Chand, Vinod K Yadav, et al. Influence of Chromium with Vermicompost on Growth and Accumulation by Brahmi. Communications in Soil Science and Plant Analysis. 2007;38:28152829.

4. Chaturvedi AD, Pal D, Penta S, et al. Ecotoxic heavy metals transformation by bacteria and fungi in aquatic ecosystem. World $J$ Microbiol Biotechnol. 2015;31(10):1595-1603.

5. Iwamoto T, Nasu M. Current bioremediation practice and perspective. $J$ Biosci Bioeng. 2001;92(1):1-8.

6. Muraleedharan TR, Iyengar L, Venkobachar C. Investigations of fungal fruiting bodies as biosorbents for the removal of heavy-metals from industrial processing streams. Sep Sci Technol. 1994;14:1893-1903.

7. Dua M, Singh A, Sethunathan N, et al. Biotechnology and bioremediation: successes and limitations. Appl Microbiol Biotechnol. 2002;59(23):143-152. 
8. Benny Chefetz, Patrick G, Hatcher, et al. Chemical and biological characterization of organic matter during composting of municipal solid waste. J Environ Qual. 1996;25(4):776-785.

9. Mani Rajkumar, Majeti Narasimha Vara Prasad, Sandhya Swaminathan, et al. Climate change driven plant-metal-microbe interactions. Environ Int. 2013;53:74-86.

10. Torsvik V, Øvreås L. Microbial diversity and function in soil: from genes to ecosystems. Curr Opin Microbiol. 2002;5(3):240-245.

11. Bouwer EJ, Zehnder AJB. Bioremediation of organic compounds-putting microbial metabolism to work. Trends Biotech. 1993;11(8):360-367.

12. Siddiquee S, Rovina K, Azad S, et al. Heavy metal contaminants removal from wastewater using the potential filamentous fungi biomass: A review. J Microb Biochem Technol. 2015;7:384-393.
13. Broda P. Using microorganism for bioremediation: the barriers to implementation. Trends Biotech. 1992;10(9):303-304.

14. Caplan JA. The worldwide bioremediation industry: prospects for profit. Trends biotech. 1993;11(8):320-323.

15. Kent AD, Triplett EW. Microbial communities and their interactions in soil and rhizosphere ecosystems. Annu Rev Microbiol. 2002;56:211-236.

16. Bertrand H, Poly F, Van VT, et al. High molecular weight DNA recovery from soils a prerequisite for biotechnological metagenomic library construction. J Microb Methods. 2005;62(1):1-11. 